\title{
Conteúdos possíveis a partir da Lei 10.639: as geo-grafias das comunidades remanescentes de quilombo no território brasileiro
}

Gabriel Siqueira Correa

\section{Resumo}

Este artigo tem o objetivo de discutir e problematizar a presença (ou ausência) dos conteúdos referentes a comunidades remanescentes de quilombo no ensino de geografia. Ele se insere na tentativa de revisar e produzir materiais para se trabalhar a Lei 10.639 no ensino de Geografia. Assim discutir comunidades remanescentes de quilombo é discutir a inserção do negro nas narrativas de formação do território brasileiro, e mostrar as alternativas para trabalhar esse tema em sala de aula. Isso deve ser feito a partir do questionamento dos discursos hegemônicos, que baseados no projeto da modernidade, invisibilizam e produzem essas comunidades como não existentes. O ensino das geografias quilombolas combate esse discurso, descolonizando nosso olhar perante os diferentes modos de vida existentes em nosso território, possibilitando a construção de outras visões de mundo.

Palavras chaves: remanescentes de quilombo; Lei 10.639; ensino; negro; território brasileiro.

\section{Abstract}

This article aims to discuss and question the presence (or absence) of content related to remnants of maroons communities in the teaching of geography. He is part of the attempt to revise and produce materials to work with Law 10.639 in teaching geography. So discuss the remaining communities of maroons, is to discuss the inclusion of black people in the narratives of formation of the Brazilian territory, and show the alternatives to work this theme in the classroom. This must be done through questioning of hegemonic discourses, which based on the project of modernity, erasing and produce these communities as non-existent. The teaching of maroons geo-grafia combat this speech, decolonizing our eyes in relation to the different modes of life existing in our territory, allowing the construction of other world views

Keyword: maroons remaining; law 12.639; teaching; Brazilian territory, black people.

\section{Introdução}

Não é incomum a associação do negro ao regime de escravidão no ensino de geografia, gerando o pensamento em que esse parece ser o único conteúdo em que ele está presente quando falamos de formação do Estado 
brasileiro. Essa narrativa que constrói, molda e perpetua uma visão de mundo, está presente ainda nos livros didáticos de geografia, reforçando essa representação, e "geo-referenciando" o negro em um tempo e espaço fixos na constituição desse território.

Nesse aspecto a Lei 10.639 mostra-se extremamente relevante, em especial quando ela afirma a importância de ensinar as lutas históricas - que também são geo-grafias dos conflitos - do negro na sociedade brasileira. Com isso pretende-se sair dessas construções em um espaço e tempo determinados, e questionar o papel subalterno exercido pelo negro nas narrativas hegemônicas sobre a formação do território brasileiro. Assim é necessário pensar em outros conteúdos, que vão além dos propostos hoje, e que sejam possíveis de serem trabalhados na aula de geografia e mais que isso, serem trabalhados em sala de aula, ou seja, incorporados ao currículo praticado.

Um dos conteúdos possíveis é sobre comunidades remanescentes de quilombos. Suas marcas se apresentam como uma grafagem espacial das lutas históricas do negro na sociedade brasileira, elemento de valorização e (re)significação da identidade negra ao longo dos processos de formação do território. E estão inseridas de maneira implícita na lei, bem como afirmando o caráter plural da nossa população, sugerido no PCN de geografia.

Assim o presente artigo pretende demonstrar conteúdos possíveis de serem trabalhados a partir das lutas quilombolas. Trazemos aqui a preocupação de que o aluno compreenda a multiplicidade de processos que culminam na existência de quase mil comunidades quilombolas, reconhecidas pelo INCRA com processos jurídicos abertos, exigindo seu território, e quase três mil comunidades representadas em outras leituras. Também propomos aqui a disputa entre espaço(s) e dialogo(s) com os discursos que hoje são hegemônicos.

\section{Comunidades remanescentes de quilombo: contra a produção de não existência em uma geografia do (e para o) sujeito.}

Quando discutimos e buscamos integrar conteúdos sobre a participação do negro em nossa geografia, acaba-se problematizando a própria narrativa de mundo que se faz presente em nosso discurso geográfico.

Este discurso construído sob o olhar hegemônico, a partir de uma perspectiva eurocêntrica, tem base na visão de mundo imposta pela modernidade/colonialidade. Esse projeto epistêmico re-cria o mundo à sua maneira, em uma narrativa linear, universal, reforçando dualismos e hierarquias que posicionam essas comunidades como atrasadas, primitivas e impossíveis de existir em uma sociedade moderna. Ou seja, as torna invisíveis perante esse olhar, que é reproduzido em nosso ensino e transmitido aos estudantes. $O$ ensino das geo-grafias quilombolas tem uma grande importância para desconstruir as normas pelas quais essa narrativa da modernidade se impõe como hegemônica.

A busca aqui é por uma geografia sendo trabalhada para os sujeitos, buscando transformar essas ausências em presenças, de maneira que essas comunidades tenham o direito de se manifestar, e acima de tudo, tenham o direito de compor à narrativa que lhes é negada. Uma narrativa que as incorpore 
como transformadoras da sociedade brasileira, transformação que ocorre hoje, pois elas são presentes. Por isso elas reinventam-se, transformam-se, e passam por processos de re-significação, afinal não vivemos em um território estático com uma única temporalidade, mas sim em um território de múltiplaterritorialidade, no qual espaços e tempos (que incluem diferentes sujeitos) cohabitam.

Esse combate à narrativa universal ocorre pela atuação nos cinco modos ou lógicas de produção de não existência ${ }^{1}$ que B. SANTOS (2003) aponta: I) monocultura do saber e do rigor do saber; II) monocultura do tempo linear; III) monocultura da naturalização das diferenças; IV) lógica da escala dominante e V) lógica produtivista.

É neste sentido que o presente trabalho traz consigo o combate às lógicas que impedem a visibilidade dessas comunidades perante aos olhares da nossa sociedade. Este combate contra essa verdadeira fábrica de produção de não existência ocorre através de conteúdos sobre as comunidades quilombolas. Busca-se aqui descolonizar e desnaturalizar nosso pensamento, reposicionando essas comunidades na formação do território brasileiro, como de fato aconteceu/acontece.

\section{A questão quilombola no Brasil}

A partir do conhecimento de lógicas que produzem o não existente, é preciso, já de inicio, tecer uma crítica a leitura linear do tempo na formação do território brasileiro. Nesta somente existem referências a determinadas geografias e alguns marcos históricos, reconhecidos e ressaltados por um discurso oficial, que é excludente. Uma leitura do território baseada na simultaneidade mostra que acontecimentos podem ocorrer dentro de um mesmo período, em diferentes espaços e escalas, com impactos e importância diversas, não possíveis de hierarquização. Ou seja, demonstra não existir apenas eventos sucessivos, como se todas as tensões e conflitos, toda diversidade da organização do território brasileiro se resumissem a alguns fatos, grafados em uma linha unidimensional, que exclui o que não é interessante pra grupo hegemônicos.

Nesse contexto de tempos sucessivos, o quilombo se apresenta enquanto único, localizado em um determinado momento da história, e é apropriado e incorporado dessa forma pelo discurso hegemônico e também midiático.

Em sala de aula, o que temos hoje tanto na geografia quanto na história, são referências a existência desse único modelo de quilombo, denominado devido ao grande conhecimento que se tem dele, o modelo Palmariano. Porém os estudos mostram que este não foi regra, mas sim exceção (ARRUTI 2002) dentre uma diversidade de quilombos espalhados pelo território brasileiro. Essa presença desmistifica a tese de que o negro era adaptável e submisso a escravidão (R. SANTOS 2009).

Esse modelo apoiado no binômio fuga-conflito remete a definição do conselho ultramarinho de Portugal de 1740, na qual quilombo era "toda habitação de negros fugidos, que passem de cinco, em parte despovoada, ainda que não tenham ranchos levantados e nem se achem pilões nele". Esta conceituação defendida por latifundiários e difundida pelo discurso hegemônico 
é utilizada para desvalorizar as lutas dos quilombolas pelo direito ao território hoje.

Em SCHMITT et. al. (2002), comentando a crítica feita por ALMEIDA (1999) temos que essa concepção de quilombo é construída sobre cinco elementos básicos:

1) a fuga; 2) uma quantidade mínima de fugidos; 3) o isolamento geográfico, em locais de difícil acesso e mais próximos de uma natureza selvagem., que da chamada civilização; 4) moradia habitual, referida no termo. rancho; 5) autoconsumo e capacidade de reprodução, simbolizados na imagem do pilão de arroz.(ALMEIDA (1999) apud SHMITT et. al. 2002, pag.2)

Essas bases são claramente restritivas, já que, por exemplo, algumas comunidades construíram relações multifacetadas (GOMES, 2006), estabelecendo uma teia de socialização, com diversos atores, como cativos, taberneiros entre outros, e palcos de lutas que conectavam comunidades negras com centros comerciais.

Esse debate e disputa por re-significações e re-interpretações acerca desse conceito, tornou-se importante após a promulgação do artigo 68 do ADCT da constituição de 1988, que reconhece o direito à propriedade para as comunidades remanescentes de quilombos, que estejam ocupando as suas terras.

A princípio pensou-se que existiriam poucas comunidades quilombolas no Brasil, mas o que vemos é um grande número de comunidades lutando por esse direito e outras muitas com possibilidades de também reivindicarem seus territórios, como indica o Mapa I A luta quilombola combate a estrutura agrária no Brasil, transformando a terra em território, compreendido por suas dimensões simbólica, cultural e política (HAESBAERT, 2006)

Mapa I: Comunidades e territórios quilombolas Auto-Identificados no Brasil. 


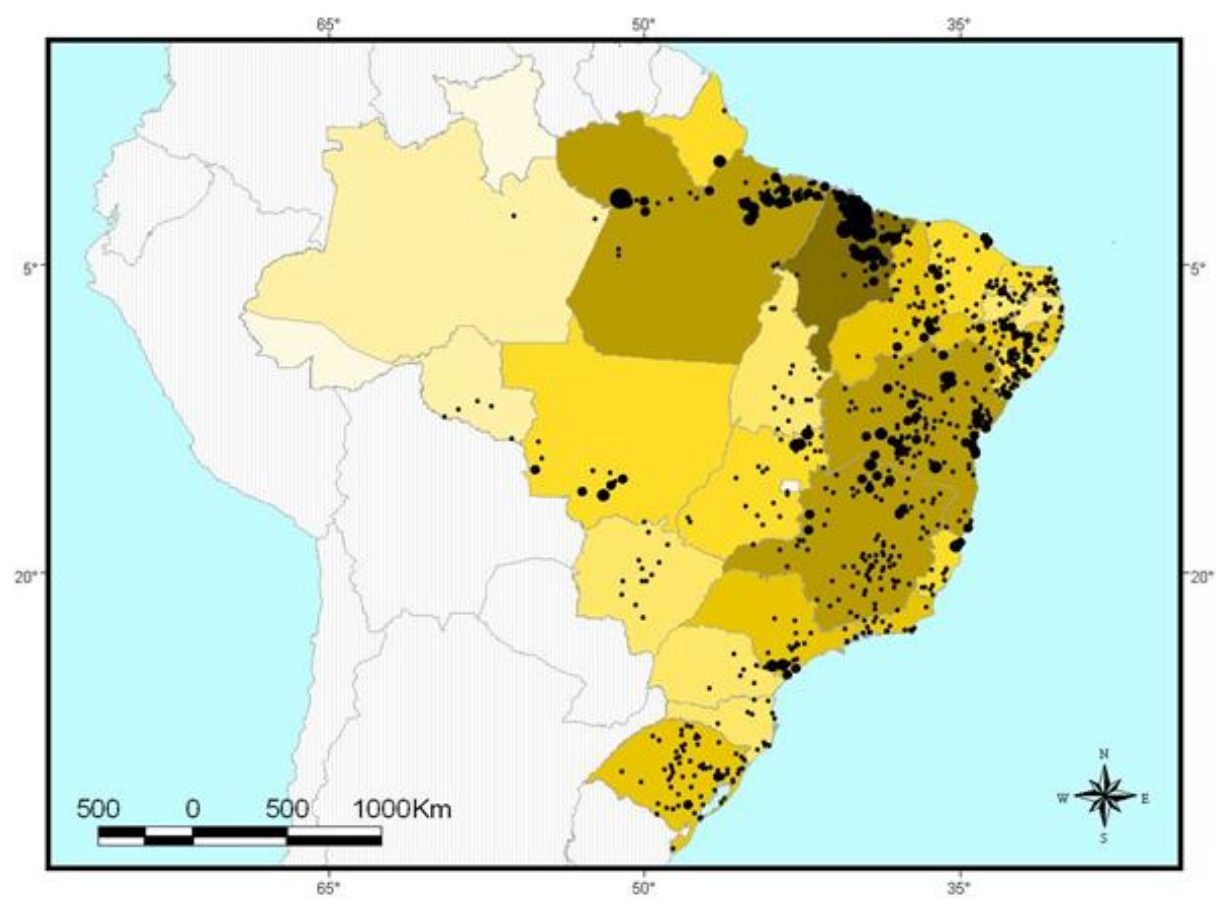

Legendas:
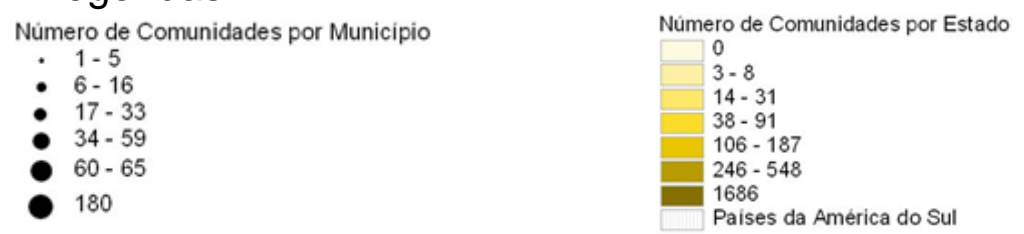

Fonte dos dados: FCP, UNB, SEPPIR, INCRA, UFAP, Programa Raízes, CEDENPA, NAEA (levantamento realizado por TRECCANI 2006)Elaboração: LEMTO/UFF (Laboratório de Estudos de Movimentos Sociais e Territorialidades)

Além do artigo 68 foram criados outros ${ }^{2}$ decretos e normas onde as comunidades remanescentes de quilombos passam a ser reconhecidas a partir da auto-atribuição, com o direito de obter não só o território onde reside, mas também o necessário para sua reprodução social, econômica e cultural. Passa a ser necessário "descolonizar" nosso olhar, enxergando quilombo a partir de sua diversidade, com características que ora se encontram e ora se desencontram, inclusos em uma multiterritorialização composta por disputas, signos, e transformações.

Uma das principais características dessas comunidades é a ligação simbólica que se tem com o território, que caracteriza as disputas como lutas por território, muito além de um pedaço de terra, como afirma ARRUTI (2002):

Grupos que lutam não só por "um pedaço de terra" ou pela reparação de erros do passado, mas também pela defesa de seus modos de vida e organização social presentes, suas formas religiosas, rituais e de manuseio da natureza, assim como por uma nova perspectiva de futuro, em que sejam considerados, dentro de suas próprias peculiaridades, como atores relevantes no momento da 
formulação e execução de políticas públicas. (ARRUTI, 2002, pag. 9)

O território é visto pela comunidade em uma dimensão simbólica e mais subjetiva, como produto de apropriação/valorização na sua relação com o espaço vivido (HAESBAERT, 2006). Essa dimensão irá variar de comunidade para comunidade, pois cada uma terá diferentes vetores de valorização, conforme a cultura do grupo predominante com relação a sua ancestralidade e origem étnica ${ }^{3}$.

Quanto à procedência do território ocupado, tanto ARRUTI (2006) quanto SANZIO (2007), colocam diversas formas de obtenção da terra ${ }^{4}$, que varia conforme a região, as grafagens resultantes dos modos de produção e organização econômica, as relações sociais que se estabeleciam entre os sujeitos, e até mesmo ao pouco valor dado a determinadas áreas. A partir disso fica claro que a formação dos quilombos vai muito além daqueles formados a partir da fuga-conflito.

Um ponto que causa surpresa é a existência de quilombos urbanos, que tem menor visibilidade frente aos que se localizam no campo. Os quilombos urbanos podem surgir em dois momento: i) devido à crescente urbanização de espaços que no passado eram considerados rurais. Assim, estas sofrem constantemente ameaças de outros grupos, com interesse especulativo na área; ii) o segundo grupo, é de comunidades que foram formadas já em espaços urbanos, situadas em " (...) cômodos e casas coletivas no centro da cidade ou núcleos semi-rurais - as roças das periferias urbanas (...)" (ROLNIK pág. 78, 2007). Eram compostas por negros que trabalhavam como escravos de ganho ou exercendo pequenas atividades livres. Já no século XX várias dessas comunidades sofreriam com as "reformas urbanas", que tinham o intuito de branquear a ocupação. No Rio de Janeiro, por exemplo, a expulsão dos centros, provocou a ocupação dos morros (ROLNIK, 2007), e de outras áreas localizadas em zonas menos valorizadas como encosta de rios.

Outra questão importante é o uso e a divisão do território. A terra de uso comum era o usual dessas comunidades, lugares onde não existiam cercas e propriedade privada, fora da lógica capitalista. Hoje é mais difícil manter essa característica, devido aos limites impostos nos laudos territoriais, que ao delimitar o território também o limitam.

As manifestações religiosas e culturais se configuram como outra marca. Festas, comemorações, ladainha, candomblé, capoeira são comuns em boa parte desses grupos. Devemos lembrar que a própria identidade quilombola traz uma valorização das práticas do ser negro nesse contexto, que passa a se enxergar de maneira diferente ${ }^{5}$.

A ancestralidade aparece como um dos pontos fundamentais, inclusive em relação à elaboração do laudo territorial no qual o tronco familiar é analisado buscando estabelecer relações de parentesco e descendência com a época da escravidão.

Por fim temos outros grupos que mesmo não possuindo relação enfática com aquilo que a historiografia denomina quilombos, foram importantes campos de relações e articulações contra a escravidão. Formaram resistência negra nos 
campos, nas senzalas, e nas terras de santo, contribuindo nas lutas, disputas, que pela sua ação em escala local, não são nem citadas em nosso ensino.

\section{O que está presente nos livros didáticos de geografia?}

A construção/revisão dos conteúdos, necessárias para a aplicação da Lei, busca disputar campos centrais na construção da educação na sociedade brasileira. Um desses campos é o livro didático, entendido aqui como principal regulador da prática docente.

Esses livros são largamente utilizados em sala de aula, extrapolando inclusive seu papel de instrumento didático e chegando a ser bibliografia obrigatória para provas de concurso público para o magistério, o que aumenta a importância das análises. Parece muitas vezes, que o conteúdo do livro é confundido com o que o professor deve aplicar em sala de aula, caracterizado então como o conhecimento que ele deve dominar.

Com base nessa pequena problematização, tentamos mostrar que a análise não é para buscar o melhor livro, ou aprovar/legitimar conhecimentos, mas para evitar que a visão de mundo a ser construída, no caso da temática do trabalho presente, seja uma visão racista e excludente.

A partir disso é importante observar o que está sendo ensinado sobre comunidades quilombolas bem como sobre a participação do negro na formação do território brasileiro, conteúdos que estão presentes nos livros didáticos do $7^{0}$ ano. No quadro abaixo apresentarei uma síntese sobre três livros muito utilizados tanto no Rio de Janeiro quanto no Brasil, são eles: Projeto Araribá e Geografia Temas, ambos da Editora Moderna, e o Projeto Radix da Editora Scipione, que estão presentes no PNLD de 2008, e contam com edições mais novas no PNLD de 2011.

QUADRO I: Quadro síntese
\begin{tabular}{|c|c|c|c|}
\hline Nome do Livro Didático & Projeto Araribá & Projeto Radix & $\begin{array}{c}\text { Construção } \\
\text { do espaço } \\
\text { Geográfico }\end{array}$ \\
\hline Autor & $\begin{array}{c}\text { Editora } \\
\text { Moderna }\end{array}$ & $\begin{array}{c}\text { Valquiria Pires \& } \\
\text { Beluce Bellucci }\end{array}$ & Melhem Adas \\
\hline Ano & 2006 & 2009 & 2006 \\
\hline $\begin{array}{c}\text { Possui conteúdos } \\
\text { referentes a } \\
\text { comunidades } \\
\text { quilombolas? }\end{array}$ & Sim & Não & Não \\
\hline $\begin{array}{c}\text { Em que eixo está } \\
\text { inserido? }\end{array}$ & $\begin{array}{c}\text { População } \\
\text { Povos } \\
\text { africanos }\end{array}$ & - & - \\
\hline $\begin{array}{c}\text { Está integrado ao texto } \\
\text { em um ponto especifico }\end{array}$ & $\begin{array}{c}\text { Ambos os } \\
\text { casos }\end{array}$ & - & - \\
\hline Possui mapas? & Sim & - & - \\
\hline
\end{tabular}




\begin{tabular}{|c|c|c|c|}
\hline Possui atividades? & Não & - & - \\
\hline $\begin{array}{c}\text { O conteúdo presente } \\
\text { deixa claras as } \\
\text { explicações referentes a } \\
\text { comunidades } \\
\text { quilombolas? }\end{array}$ & Não & - & - \\
\hline $\begin{array}{l}\text { Referência a democracia } \\
\text { racial? De forma direta } \\
\text { ou indireta? }\end{array}$ & Sim - direta & Sim & - \\
\hline $\begin{array}{l}\text { Criticando ou } \\
\text { naturalizando? }\end{array}$ & Criticando & Naturalizando & - \\
\hline De que forma? & Texto e gráfico & $\begin{array}{c}\text { Identidade } \\
\text { comum/desigualdad } \\
\text { e apenas pelo fator } \\
\text { econômico }\end{array}$ & - \\
\hline $\begin{array}{c}\text { Existem gráficos para } \\
\text { ilustrar? }\end{array}$ & Sim & - & - \\
\hline Se existem quais são? & $\begin{array}{l}\text { Distribuição de } \\
\text { renda por cor, } \\
\text { dividido por } \\
\text { regiões }\end{array}$ & - & - \\
\hline $\begin{array}{c}\text { Existe abordagem } \\
\text { indireta/direta sobre } \\
\text { branqueamento do } \\
\text { território? }\end{array}$ & $\begin{array}{l}\text { Sim - Direta e } \\
\text { Indireta }\end{array}$ & Sim - Indireta & Sim - Indireta \\
\hline $\begin{array}{l}\text { Há destaque para a } \\
\text { imigração européia? }\end{array}$ & $\begin{array}{l}\text { Sim - presente } \\
\text { em alguns } \\
\text { pontos de } \\
\text { conteúdos }\end{array}$ & $\begin{array}{l}\text { Sim - presente em } \\
\text { alguns pontos de } \\
\text { conteúdos }\end{array}$ & $\begin{array}{l}\text { Sim - } \\
\text { presente em } \\
\text { alguns pontos } \\
\text { de conteúdos }\end{array}$ \\
\hline $\begin{array}{l}\text { Quais povos são } \\
\text { retratados? }\end{array}$ & $\begin{array}{l}\text { Italianos e } \\
\text { alemães }\end{array}$ & Italianos e alemães & $\begin{array}{l}\text { Italianos, } \\
\text { alemães }\end{array}$ \\
\hline $\begin{array}{c}\text { Existe referência } \\
\text { população negra ao } \\
\text { longo do livro? }\end{array}$ & Sim & Sim & Sim \\
\hline Como ela é retratada? & $\begin{array}{l}\text { Sob a ótica da } \\
\text { cultura, ou } \\
\text { imagens da } \\
\text { escravidão }\end{array}$ & $\begin{array}{c}\text { Sob a ótica da } \\
\text { cultura, e através da } \\
\text { pobreza }\end{array}$ & $\begin{array}{l}\text { Imagens de } \\
\text { escravidão - } \\
\text { Presença no } \\
\text { Sul }\end{array}$ \\
\hline $\begin{array}{l}\text { Quais povos são } \\
\text { retratados vindos da } \\
\text { África? }\end{array}$ & $\begin{array}{l}\text { Congo, Angola, } \\
\text { Moçambique }\end{array}$ & $\begin{array}{c}\text { Sob a categoria de } \\
\text { africanos }\end{array}$ & $\begin{array}{l}\text { Sob a } \\
\text { categoria } \\
\text { africanos }\end{array}$ \\
\hline
\end{tabular}

Além das informações presentes no quadro, podemos identificar que na maior parte dos livros as referências a populações negras estão ligadas a 
escravidão ou sob uma ótica cultural - reduzida sempre aos exemplos de feijoada, samba e capoeira. As imagens presentes reforçam esse caráter, com a participação do negro reduzida ao período da escravidão ou áreas de miséria.

Em todos os livros encontram-se referências da imigração alemã e italiana, na maior parte das vezes substituindo o trabalho escravo no espaço da cafeicultura, mas de maneira geral ocupando também os espaços no Sul do Brasil.

Dos três livros apenas o Araribá possui conteúdos sobre comunidades quilombolas, questiona a democracia racial, e insere idéias sobre o branqueamento do território. Porém ficou claro que existem muitas contradições ao longo do livro, e a maior parte dos conteúdos não é apresentado de forma consistente, podendo ser interpretados de diversas maneiras, inclusive pejorativas.

De maneira geral, a ausência da população negra pode ser vista sob a perspectiva de branqueamento da população, como afirma SANZIO (2007):

"A história brasileira somente recentemente está se referindo aos quilombos como se não fossem algo do passado. A referência criada no processo de ensino faz parecer que eles não fazem mais parte da vida do Pais. Não podemos perder de vista que esse aparente desaparecimento das populações negras, principalmente dos livros didáticos, faz parte da estratégia de branquamento da população." (SANZIO, 2007, pag.116)

Uma das formas de combater esse projeto de branqueamento e racismo refinado nos livros didáticos, bem como integrar e representar o negro na esfera do território nacional é o ensino sobre comunidades quilombolas, ausente mesmo quando presente - dessas coleções.

\section{Ensino sobre comunidades remanescentes de quilombo e Geografia}

Com base nas informações apresentadas, podemos - e devemos abordar diversas questões em sala de aula, buscando integrar o negro ao território brasileiro mostrando lutas, processos de resistências e presença/grafagens no espaço. Porém cabe ressaltar que essa discussão precisa ser realizada em todas as séries, em diversos assuntos, para que o conteúdo não fique solto e disperso no pensamento do aluno, preso a um período histórico, com apenas uma referência em todo processo de ensinoaprendizagem.

Ademais o ensino sobre comunidades remanescentes de quilombo vem combater a produção de não existência, já explicadas aqui, através de modelos alternativos de organização da sociedade, como as comunitárias, terras de uso comum etc; de modelos de conhecimento, com suas práticas medicinais sendo valorizadas, suas diferentes crenças; diferentes formas de relações com a natureza, que não seja a predatória, resistindo às pressões de indústrias de alta tecnologia; valorização das lutas em escalas locais, retirando da invisibilidade 
grupos outrora desconhecidos da população. Abaixo abordamos alguns pontos de conteúdos possíveis para trabalhar essas comunidades em sala de aula,

\section{I) Explicação do conceito de território}

$\rightarrow$ Exemplo de territorialização: expressando as relações simbólicas, econômicas que essas comunidades possuem, bem como sua relação com a natureza. Podem ser explicadas em todos os anos do ensino fundamental, pois o próprio conceito de território perpassa por todo o conteúdo.

$\rightarrow$ Outras lógicas de uso do território: que não seja a dominante capitalista, em busca de uma produtividade cega. Os territórios também passam a ser "lugares da memória" frente ao território imemorial, cada vez mais presente em nossa sociedade, bem como a característica principal que é a inalienabilidade das terras, que vai contra a lógica da propriedade privada, não podendo ser vendida por um de seus integrantes.

\section{II) Formação do território brasileiro}

$\rightarrow$ Resistência ao processo de escravidão: mostrando a proporção de quilombos no Brasil, baseado em diversas leituras diferentes, bem como outras formas de resistência, das quais o negro foi protagonista, desmistificando a tese de que o negro era adaptável à escravidão.

$\rightarrow$ Marco da presença negra no território e as grafagens no espaço: Mostrar a presença da população negra em todo território brasileiro, e não somente em um período histórico, mas sim durante todo o processo de formação e organização do espaço brasileiro, nos estados e atualmente com as comunidades remanescentes de quilombos nos municípios. A partir disso, mostrar como a presença negra geo-grafou o espaço brasileiro.

$\rightarrow$ Diversidade étnica: A partir dos quilombos, mostrar os diferentes grupos dos escravos trazidos do continente africano (como os bantos), e as estratégias em separá-los executada pelo governo brasileiro. Essas diferenças vão contribuir para as diferentes estratégias de lutas dessas comunidades no território. Essas informações vão de encontro a uma das críticas feitas aos livros didáticos de geografia, que retratam esses grupos, apenas como africanos, enquanto todos os outros grupos, como italianos e alemães são identificados.

$\rightarrow$ Problematizando a questão agrária do Brasil no período atual: Mostrando as pressões/agressões que essas comunidades vêm sofrendo, frente a uma forte pressão da bancada ruralista contra os direitos obtidos. $O$ papel do Estado ${ }^{6}$ também deve ser questionado como fornecedor da infra-estrutura necessária a implementação do meio técnico-científico-informácional em que as grandes empresas atuam apenas na busca pela produtividade, sem importar a manutenção do meio físico, já que sua lógica é externa aos meio que atua (M. SANTOS 2004), desterritorializando comunidades tradicionais, como os quilombolas.

$\rightarrow$ Explicar políticas de branqueamento: que desterritorializaram muitas dessas comunidades, através de reformas urbanas, e políticas racistas de imigração, com objetivo de branquear o território, sua imagem e história. Esses imigrantes seriam direcionados a áreas onde supostamente ${ }^{7}$ não haveria mão de 
obra disponível ou em vazios demográficos, lugares em que existiam quilombos ou indígenas.

$\rightarrow$ Explicar a dinâmica de urbanização e especulação: em que muitas das áreas localizadas em comunidades quilombolas, que eram antigas zonas rurais passaram a sofrer, devido a urbanização e valorização, com conseqüente pressão dos agentes imobiliários. Fato que ocorre principalmente com as comunidades que não tiveram títulos expedidos (a maioria), como a localizada na Pedra do Sal, zona portuária no Rio de Janeiro, local com grandes reformas e investimentos previstos para os Jogos Olímpicos de 2016.

$\rightarrow$ Diversidade do campo brasileiro: pois a partir da identificação das comunidades quilombolas, pode-se identificar uma gama de grupos como os ribeirinhos, os seringueiros etc.

III) Movimentos sociais e as comunidades remanescentes de quilombo

$\rightarrow$ Localização dessas comunidades: esse caráter tem que ser enfatizado através da utilização de mapas, para indicar a presença em lugares os quais é negada a sua participação. A valorização da ação local, como forma de movimento social também é importante, pois em muitos momentos retira da invisibilidade uma comunidade perante aos olhos dos moradores de determinados estados, como no Paraná (mapa II); destacando a importância da utilização de mapas em escala estadual.

Mapa II: Comunidades e territórios quilombolas Auto-Identificados no Paraná.

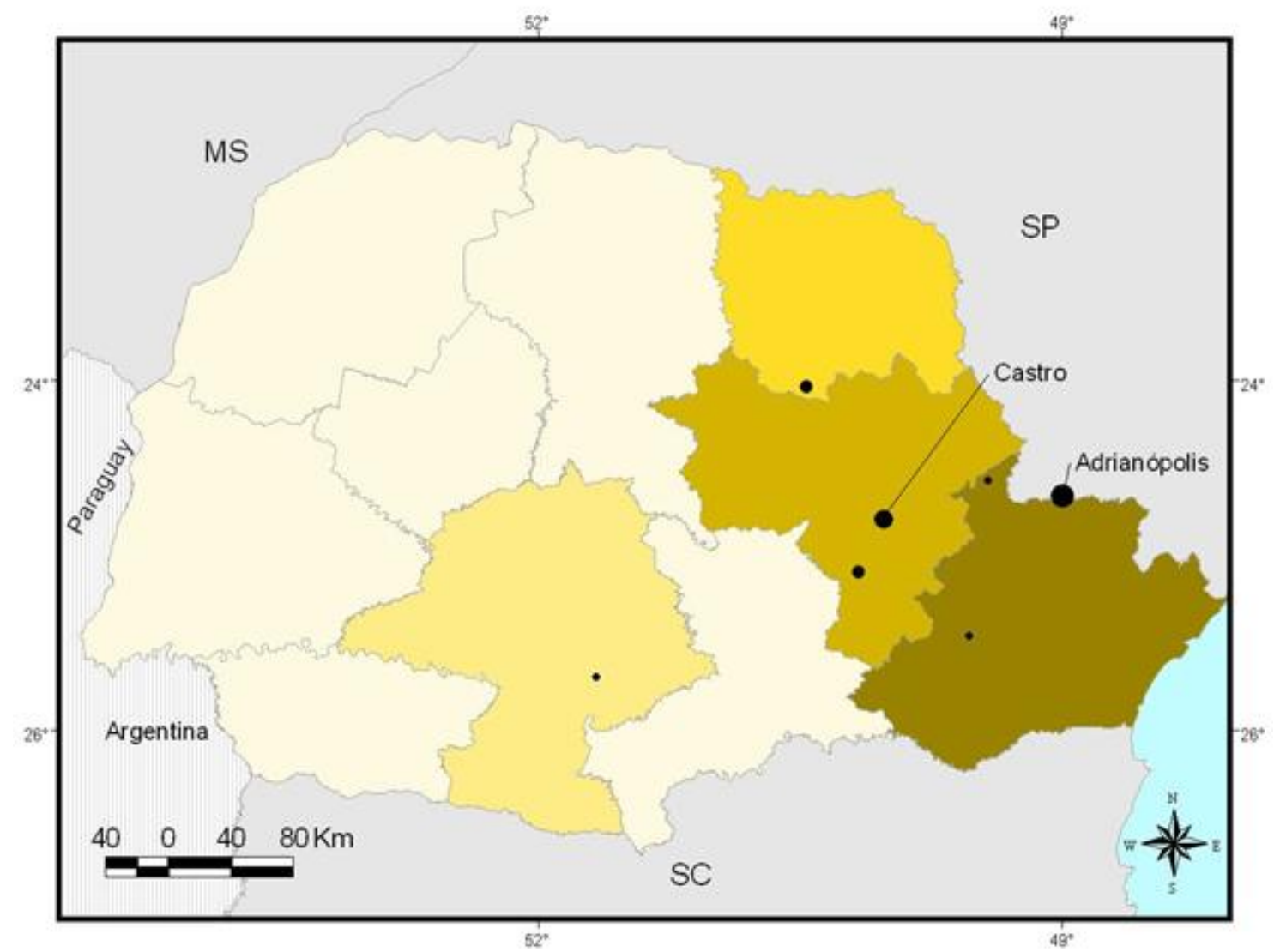

Legenda:

$\begin{array}{lll} & \begin{array}{l}\text { Número de Comunidades por Municipio } \\ \text { TAMOIOS. }\end{array} & 1 \\ & \bullet & 3 \\ & \end{array}$

Número de Comunidades por Mesoregiåo 
Fonte dos dados: FCP, UNB, SEPPIR, INCRA,UFAP, Programa Raízes, CEDENPA, NAEA (levantamento realizado por TRECCANI 2006)

Elaboração: LEMTO/UFF (Laboratório de Estudos de Movimentos Sociais e Territorialidades)

$\rightarrow$ Mostrar o que são as comunidades quilombolas hoje: explicando e problematizando os diferentes processos de formação, produção econômicas, práticas sociais, bem como as diversas origens. A descolonização dos saberes também é um foco importante para ser abordado, dando destaque para a história oral que essas comunidades possuem, que expressam informações preciosas sobre o conhecimento do território e do modo de vida, bem como realçam os saberes tradicionais;

$\rightarrow$ Indicar as lutas atuais: como os conflitos vêm ocorrendo, as repercussões na mídia, as posições que grupos da elite defendem e sob quais discursos eles se apóiam. Os diferentes desafios que enfrentam as comunidades quilombolas rurais e urbanas, os agentes que atuam nesses conflitos como órgãos ambientais, políticos, agentes imobiliários, grandes proprietários de terra, grandes empresas, quais são as dificuldades que as comunidades enfrentam nessas lutas, as pressões, as coerções etc.

$\rightarrow$ Problematização das formas de conquistas dos direitos territoriais: é importante mostrar ao aluno que para conseguir esse território as comunidades passam por processos de reconhecimento, que colocam diversos empecilhos para a aquisição do título definitivo. Dois campos são principais nessa disputa, o primeiro é o Laudo Territorial, onde características como ancestralidade, oralidade e relações de parentesco são postas em destaque. O campo jurídico é outro a ser explorado, mostrando quais direitos essas comunidades possuem e as legislações que os regem..

Esses são apenas alguns pontos de conteúdos em que podemos trabalhar a questão quilombola - seja na abordagem do conceito de território, na formação do território brasileiro, ou ao tratar de movimentos sociais - sendo necessário integrar esses conteúdos nas aulas, com o objetivo de mostrar a presença negra durante todo o processo de formação do território brasileiro.

\section{Considerações Finais}

As lutas para a aplicação da lei ainda são muitas, mas as possibilidades que surgem também, tornando importante sua integração a geografia, permitindo a valorização da identidade negra e a presença de sua grafia no território brasileiro, o que se tentou apagar e negar até hoje.

Portanto, mais que um instrumento para reposicionar o aluno negro no mundo da educação, a lei pode ser uma ferramenta para enfim, posicionar esse aluno no território brasileiro, e a geografia é fundamental nesse processo. 
O ensino sobre comunidades remanescentes de quilombo, suas lutas, resistências e disputa por território aparecem como importante conteúdo a ser utilizado para desmistificar diversas visões presentes no discurso hegemônico. Lembrando que esses conteúdos devem estar presentes nas aulas e não em um momento especifico do calendário escolar, como o dia 20 de novembro, como se este só fizesse parte de um momento da história.

Buscamos mostrar como a Lei.10.639 e o ensino sobre as comunidades remanescentes de quilombos, são um caminho possível para uma educação anti-racista. Mas para isso ocorrer é preciso pôr esses debates e as práticas contestatórias em sala de aula, discutindo e debatendo uma geo-grafia dos conflitos e para os sujeitos.

\section{Notas}

I - É possível várias ligações entre esses modos de produção de não existência e as formas como os currículos estão colocados em nossa sociedade II - Entre os mais significativos, encontra-se o decreto 4887/03,e a instituição normativa no 20 de 2005

III - As comunidades remanescentes de quilombo serão diferenciadas, primeiro por serem quilombolas, e segundo por serem diferentes entre elas mesmas, devido a origens distintas. "A semelhança entre essas comunidades decorre da deformação do olhar que a ação hegemônica da sociedade mais ampla provoca. O conhecimento dessas comunidades, por isso mesmo, reclama o pluralismo como principio, a diversidade como pressuposto e a diferença como episteme" (LEITE, 2004, pág. 13)

IV - A origem do território pode ser de terras doadas por ordens religiosas, terras devolutas, ocupação de fazendas abandonadas ou falidas, terras compradas através da prestação de serviço, terras compradas por ex-escravos alforriados entre outras.

V - Isso fica expresso no caso relatado por CARVALHO (2008) na comunidade quilombola Chácara das Rosas, localizada na região sul. Esse grupo que sofria forte preconceito, chegando a ser chamado de planeta dos macacos ao assumir a identidade quilombola passou a "ocupar um novo lugar nas relações com os vizinhos, na política local, perante órgãos estaduais e federais, no imaginário nacional e no seu próprio imaginário." (CARVALHO, 2008, pag. 223)

VI - Desta forma, o Estado atua no fornecimento da estrutura necessária à implementação e consolidação de um macro projeto regido pela lógica capitalista sobre um território outrora gerido pela ética das comunidades tradicionais, camponesas ou rústicas, que utilizavam a terra e outros recursos naturais como o sustentáculo de sua vida cotidiana. As terras de uso comum foram forçadas a se transformar em propriedades privadas. O ambiente físico, diretamente vinculado à manutenção do modo de vida local, foi exaurido e esgotado pela nova lógica de produção. (FERREIRA, 2002, pág. 160)

VII - Isso ocorreu principalmente nos estados do RJ e SP, com a imigração de italianos para trabalhar nas lavouras de café. Na verdade o objetivo era branquear a população, já que existia uma grande quantidade de ex-escravos nessas áreas. 


\section{Referências}

ARRUTI, José. Maurício. Mocambo: antropologia e história do processo de formação quilombola. São Paulo: Edusc, 2006

"Territórios Negros". In: KOINONIA. Territórios

Negros - Egbé: Relatório Territórios Negros. Rio de Janeiro: Koinonia, 2002.

CARVALHO, Ana Paula Comin de. Do "Planeta dos Macacos" a "Chácara das Rosas":de um território negro a um quilombo urbano. In SILVA, Gilberto Ferreira et al . RS Negro: cartografias sobre a produção do conhecimento. Porto Alegre: EDIPUCRS, 2008.

FERREIRA, Simone Raquel Batista. Da fartura a escassez: a agroindústria de celulose e o fim dos territórios comunais no Extremo Norte do Espírito Santo. 2002. Dissertação de mestrado - Faculdade de Filosofia, Letras e Ciências Humanas, Departamento de Geografia.

GOMES, Flávio dos S. Histórias de quilombolas: mocambos e comunidades de senzalas no Rio de Janeiro, século XIX. São Paulo: Companhia das Letras, 2006 HASBAERT, Rogério. O mito da desterritorialização: do "fim dos territórios" a multiterritorialidade. Rio de Janeiro: Bertrand Brasil, 2006.

MIGNOLO, Walter D. Os esplendores e as misérias da "ciência": colonialidade, geopolítica do conhecimento e pluro-versalidade epistêmica..IN: SANTOS, Boaventura de Souza. Conhecimento prudente para uma vida decente. Cortez, 2003

ROLNIK, Raquel. Territórios negros nas cidades brasileiras: etnicidade e cidade em São Paulo e Rio de Janeiro. In SANTOS, Renato Emerson (org.) Diversidade, espaço e relações étnico-raciais: O Negro na Geografia do Brasil. Belo Horizonte: Autêntica, 2007.

SANTOS, Boaventura de Souza. Para uma sociologia das ausências e uma sociologia das emergências IN: Conhecimento prudente para uma vida decente. Cortez, 2003

SANTOS, Milton A natureza do Espaço: Técnica e Tempo, Razão e Emoção. 4a ed. São Paulo: Editora da Universidade de São Paulo, 2004.

SANTOS, Renato Emerson dos. "O ensino de Geografia e as relações raciais: reflexões a partir da Lei 10.639". In: Diversidade, espaço e relações étnico-raciais: o negro na Geografia do Brasil. Belo Horizonte: Autêntica, 2007Rediscutindo o Ensino de Geografia: Temas da Lei 10.639.

2009 (Mimeo)

SANZIO, Rafael. Territórios étnicos: o espaço dos quilombos no Brasil In: SANTOS, Renato Emerson (org.) Diversidade, espaço e relações étnico-raciais: O Negro na Geografia do Brasil. Belo Horizonte: Autêntica, 2007.

SCHMITT, Alessandra et al. A atualização do conceito de quilombo: identidade e territórios das definições teóricas. In: Ambiente e Sociedade, Ano V, Número 10, 2002. 